Pacific Journal of Mathematics

EXTENDING WHITNEY MAPS 


\title{
EXTENDING WHITNEY MAPS
}

\author{
L. E. WARD, JR.
}

The following theorems are proved. (1) If $X$ is a continuum then any Whitney map for $C(X)$, the space of subcontinua of $X$, can be extended to a Whitney map for $2^{x}$, the space of nonempty closed subsets of $X$. (2) If $Y$ is a continuum and $X$ is a subcontinuum of $Y$ then any Whitney map for $C(X)$ (resp., $2^{X}$ ) can be extended to a Whitney map for $C(Y)$ (resp., $\left.2^{X}\right)$. The proofs entail recasting these problems in the more inclusive setting of partially ordered spaces and then employing results of Nachbin.

1. Introduction. In this paper a continuum is a compact connected metric space. If $X$ is a continuum then $2^{X}$ (respectively, $C(X)$ ) is the hyperspace of nonempty closed subsets (respectively, subcontinua) of $X$, endowed with the Hausdorff metric. If $\Lambda \subset 2^{X}$ and if $\Lambda$ contains all of the singleton subsets of $X$, then a Whitney map for $\Lambda$ is a continuous function $\omega: \Lambda \rightarrow[0,+\infty)$ such that $\omega(\{x\})=0$ for each $x \in X$ and $\omega(A)<\omega(B)$ whenever $A$ and $B$ are members of $\Lambda$ and $A$ is properly contained in $B$.

Among the many interesting and heretofore unsolved problems in the theory of hyperspaces are the following. Nadler ([4], 14.71.5) has asked if every Whitney map for $C(X)$ can be extended to a Whitney map for $2^{X}$. A related question (due to Bruce Hughes and communicated to me by Professor Carl Eberhart) asks whether a Whitney map for $C(X)$ can always be extended to a Whitney map for $C(Y)$ if $X$ is a subcontinuum of $Y$. We shall answer these questions in the affirmative. The keystone of our approach is to recast the problem in the more general setting of partially ordered spaces, whereupon Nachbin's order-theoretic analog of Tietze's theorem [3] provides an essential ingredient of the proof.

At this point it is worth recalling that in [6] we promoted the notion-certainly not new-that some problems concerning hyperspaces become more tractable if the hyperspace is regarded as a special type of partially ordered space. There is a substantial literature dealing with the latter which can then be utilized. The present paper constitutes further evidence in support of this view.

2. Definitions and known results. A partially ordered space is a topological space $P$ endowed with a partial order $\leqq$ whose graph is a closed subset of $P \times P$. It is known (see, for example, [2], p. 167) that if $X$ is a regular Hausdorff space then $2^{X}$ is a partially 
ordered space with respect to inclusion. If $P$ is a partially ordered space and $x \in P$, we write $L(x)=\{p \in P: p \leqq x\}$ and $M(x)=\{p \in P: x \leqq p\}$, and if $A \subset P$ then

$$
\begin{aligned}
& L(A)=\cup\{L(x): x \in A\}, \\
& M(A)=\cup\{M(x): x \in A\} .
\end{aligned}
$$

An element $m$ of a partially ordered space $P$ is minimal (maximal) if, whenever $x \in P$ and $x \leqq m(m \leqq x)$, it follows that $x=m$. The set of minimal elements of $P$ is denoted Min $P$; the set of maximal elements is denoted $\operatorname{Max} P$. It is known [5] that if $P$ is compact and $x \in P$ then $L(x)$ meets Min $P$ and $M(x)$ meets Max $P$.

A Whitney map for a partially ordered space $P$ is a continuous function $\omega: P \rightarrow[0,1]$ which satisfies

(i) if $x \in \operatorname{Min} P$ then $\omega(x)=0$,

(ii) if $x \in \operatorname{Max} P$ then $\omega(x)=1$,

(iii) if $x<y$ in $P$ then $\omega(x)<\omega(y)$.

It is obvious that if $P=2^{X}$ for some continuum $X$ and if $\omega$ satisfies (i), (ii) and (iii), then $\omega$ is a Whitney map in the hyperspace sense. Moreover, if $X$ is a continuum then a Whitney map for $2^{X}$ is, up to a constant factor, a Whitney map in the sense of partially ordered spaces.

It is well-known (for example, see the discussion in [4], pp. 2427) that $2^{X}$ admits a Whitney map whenever $X$ is a continuum. In a recent note [6] the author generalized this result to an appropriate class of partially ordered spaces, as follows.

THEOREM 2.1. If $P$ is a compact metric partially ordered space such that $\operatorname{Min} P$ and $\operatorname{Max} P$ are disjoint closed sets, then $P$ admits a Whitney map.

At this point it is helpful to take cognizance of several results of Nachbin [3] for partially ordered spaces. The statements given here for Nachbin's results differ slightly from those in [3], but they follow easily. In particular, Nachbin's order-theoretic version of Tietze's Theorem (2.4) is stated here only for compact partially ordered spaces, whereas the original result was established in the more general setting of "normally ordered" spaces.

THEOREM 2.2. If $K$ is a compact subset of a partially ordered space, then $L(K)$ and $M(K)$ are closed sets.

THEOREM 2.3. If $x$ and $y$ are elements of a compact partially ordered space and if $M(x) \cap L(y)=\varnothing$, then there are disjoint open sets $U$ and $V$ such that $x \in U=M(U)$ and $y \in V=L(V)$. 
If $A$ and $B$ are partially ordered sets then a function $f: A \rightarrow B$ is said to be order-preserving if, whenever $x \leqq y$ in $A$, it follows that $f(x) \leqq f(y)$.

THEOREM 2.4. If $Q$ is a closed subset of the compact partially ordered space $P$ and if $f: Q \rightarrow[0,1]$ is a continuous order-preserving function, then there exists a continuous order-preserving function $g: P \rightarrow[0,1]$ such that $g \mid Q=f$.

3. Extending Whitney maps for partially ordered spaces. Our main result is the following theorem.

THeOREM 3.1. Let $P$ be a compact metric partially ordered space such that $\operatorname{Min} P$ and $\operatorname{Max} P$ are disjoint closed sets and let $Q$ be $a$ closed subset of $P$ such that $\operatorname{Min} Q \subset \operatorname{Min} P$ and $\operatorname{Max} Q \subset \operatorname{Max} P$. Then a Whitney map for $Q$ can be extended to a Whitney map for $P$.

The proof of (3.1) depends on a delicate application of (2.4). To facilitate this we first obtain a lemma.

Lemma 3.2. Suppose $P$ is a compact partially ordered space such that Min $P$ and $\operatorname{Max} P$ are disjoint closed sets, $Q$ is a closed subset containing (Min $P) \cup(\operatorname{Max} P)$, and suppose $A$ and $B$ are disjoint nonempty closed subsets such that $A=M(A)$ and $B=L(B)$. If $f: Q \rightarrow$ $[0,1]$ is a continuous order-preserving function such that $f \mid(\operatorname{Min} P) \equiv$ 0 and $f \mid(\operatorname{Max} P) \equiv 1$, then $f$ admits a continuous order-preserving extension $\bar{f}: P \rightarrow[0,1]$ such that $\bar{f}(a) \geqq \inf f \mid(A \cap Q)$ for each $a \in A$ and $\bar{f}(b) \leqq \sup f \mid(B \cap Q)$ for each $b \in B$.

Proof. By (2.4) the function $f \mid(A \cap Q)$ admits a continuous orderpreserving extension

$$
f_{1}: A \longrightarrow[\inf f \mid(A \cap Q), 1],
$$

and the function $f \mid(B \cap Q)$ admits a continuous order-preserving extension

$$
f_{0}: B \longrightarrow[0, \sup f \mid(B \cap Q)] .
$$

The mapping $f \cup f_{0} \cup f_{1}$ is a continuous order-preserving function defined on the closed set $Q \cup A \cup B$, and another application of (2.4) yields the desired function $\bar{f}: P \rightarrow[0,1]$.

We turn now to proof of (3.1). Let $\omega_{Q}$ be a Whitney map for $Q$. We may extend $\omega_{Q}$ at once to $(\operatorname{Min} P) \cup(\operatorname{Max} P)$ by letting $\omega_{Q} \mid(\operatorname{Min} P) \equiv 0$ and $\omega_{Q} \mid(\operatorname{Max} P) \equiv 1$, so there is no loss of generality 
if we assume $Q$ contains $(\operatorname{Min} P) \cup(\operatorname{Max} P)$, and hence (3.2) may be applied. We employ a variation on an argument due to Carruth [1]. Suppose $\mathscr{C}$ is a countable base for the topology of $P$, and let $\mathscr{B}$ denote the family of all pairs $(U, V)$ of members of $\mathscr{C}$ such that $M(\bar{U}) \cap L(\bar{V})=\varnothing$. Then $\mathscr{B}$ is also countable and we may enumerate its elements:

$$
\mathscr{B}=\left\{\left(U_{n}, V_{n}\right): n=1,2, \cdots\right\} .
$$

By (2.2) the sets $M\left(\bar{U}_{n}\right)$ and $L\left(\bar{V}_{n}\right)$ are closed, so by (3.2), for each positive integer $n$ there is a continuous order-preserving extension $f_{n}: P \rightarrow[0,1]$ of $\omega_{Q}$ such that

$$
\begin{array}{lll}
f_{n}(a) \geqq \inf \omega_{Q} \mid\left(M\left(\bar{U}_{n}\right) \cap Q\right) & \text { if } & a \in M\left(\bar{U}_{n}\right), \\
f_{n}(b) \leqq \sup \omega_{Q} \mid\left(L\left(\bar{V}_{n}\right) \cap Q\right) & \text { if } & b \in L\left(\bar{V}_{n}\right) .
\end{array}
$$

Define $\omega_{P}: P \rightarrow[0,1]$ by $\omega_{P}=\sum 2^{-n} f_{n}$. Obviously $\omega_{P}$ is continuous and $\omega_{P}$ is an extension of $\omega_{Q}$. Since each $f_{n}$ is order-preserving, so is $\omega_{P}$. Thus it remains to show that if $x<y$ in $P$ then $\omega_{P}(x)<$ $\omega_{P}(y)$. Clearly, it is sufficient to verify the existence of a positive integer $n$ such that $f_{n}(x)<f_{n}(y)$.

Let $t_{x}=\sup \omega_{Q} \mid(L(x) \cap Q)$ and $t_{y}=\inf \omega_{Q} \mid(M(y) \cap Q)$. Since $\omega_{Q}$ is a Whitney map it follows that $t_{x}<t_{y}$. Let $0<\varepsilon<\left(t_{y}-t_{x}\right) / 2$. By (2.3) there are disjoint open sets $U$ and $V$ such that $x \in V=L(V)$ and $y \in U=M(U)$, and by a straightforward compactness argument we may assume that $\omega_{Q}(V \cap Q) \subset\left[0, t_{x}+\varepsilon\right)$ and $\omega_{Q}(U \cap Q) \subset\left(t_{y}-\varepsilon, 1\right]$. It follows that there is a positive integer $n$ such that $x \in V_{n} \subset \bar{V}_{n} \subset V$ and $y \in U_{n} \subset \bar{U}_{n} \subset U$, from which we conclude that

$$
f_{n}(x) \leqq t_{x}+\varepsilon<t_{y}-\varepsilon \leqq f_{n}(y) .
$$

The proof is complete.

CoROLLARY 3.3. If $X$ is a continuum then any Whitney map for $C(X)$ can be extended to a Whitney map for $2^{X}$.

CoROLlary 3.4. If $Y$ is a continuum and $X$ is a subcontinuum of $Y$, then any Whitney map for $C(X)$ (resp., $2^{X}$ ) can be extended to a Whitney map for $C(Y)\left(\right.$ resp., $\left.2^{Y}\right)$.

Proof. We give the proof for $C(X)$; the proof for $2^{X}$ follows similarly. Clearly $C(X)$ is a closed subset of $C(Y)$ and $\operatorname{Min} C(X) \subset$ $\operatorname{Min} C(Y)$. However, $\operatorname{Max} C(X)=\{X\}$ is not a subset of $\operatorname{Max} C(Y)$. This deficiency is readily corrected by defining $Q=C(X) \cup\{Y\}$ so that $\operatorname{Max} Q=\{Y\}=\operatorname{Max} C(Y)$. If $\omega_{X}$ is a Whitney map for $C(X)$ with $\omega_{X}(X)=1$, let $\omega_{Q}: Q \rightarrow[0,1]$ be defined by 


$$
\begin{gathered}
\omega_{Q} \mid C(X)=\frac{1}{2} \omega_{X}, \\
\omega_{Q}(Y)=1 .
\end{gathered}
$$

Theorem 3.1 now applies and $\omega_{Q}$ extends to a Whitney map $\omega_{Y}$ for $C(Y)$. Clearly, $2 \omega_{Y}$ is the desired extension of $\omega_{X}$.

It is worth remarking that the family of mappings $f_{n}: P \rightarrow[0,1]$ does not, in general, distinguish points of $P$ and hence does not generate an order homeomorphism of $P$ into the Hilbert cube. However, Carruth [1] has shown that such order homeomorphisms exist for all compact metric partially ordered spaces. The following question arises naturally.

Problem 3.5. Let $\omega_{P}$ be a Whitney map for the compact metric partially ordered space $P$. Under what conditions does there exist an order-homeomorphism $\varphi: P \rightarrow H$, the Hilbert cube, so that $\omega \mid \varphi(P)=$ $\omega_{P} \varphi^{-1}$, where $\omega: H \rightarrow[0,1]$ is the Whitney map defined by $\omega(x)=$ $\sum 2^{-n} x_{n}$ ?

\section{REFERENCES}

1. J. H. Carruth, A note on partially ordered compacta, Pacific J. Math., 24 (1968), 229-231.

2. K. Kuratowski, Topology I, Academic Press, 1966.

3. L. Nachbin, Topology and Order, Van Nostrand, 1965.

4. S. B. Nadler, Jr., Hyperspaces of Sets, Dekker, 1978.

5. L. E. Ward, Jr., Partially ordered topological spaces, Proc. Amer. Math. Soc., 5 (1954), 144-161.

6. —, A note on Whitney maps, Canad. Math. Bull., to appear.

Received September 17, 1979.

UNIVERSITY OF OREGON

EUGENE, OR 97403 



\title{
PACIFIC JOURNAL OF MATHEMATICS
}

\section{EDITORS}

\author{
DoNALD BABBITT (Managing Editor) \\ University of California \\ Los Angeles, CA 90024 \\ Hugo RossI \\ University of Utah \\ Salt Lake City, UT 84112 \\ C. C. MOORE and ANDrew OGG \\ University of California \\ Berkeley, CA 94720
}

J. DugundJI

Department of Mathematics

University of Southern California

Los Angeles, CA 90007

R. FINN and J. MILGRAM

Stanford University

Stanford, CA 94305

\section{ASSOCIATE EDITORS}
R. Arens
E. F. BeCKenbaCH
B. H. NeumanN
F. WOLF
K. YoSHIDA

\section{SUPPORTING INSTITUTIONS}

UNIVERSITY OF ARIZONA

UNIVERSITY OF BRITISH COLUMBIA

CALIFORNIA INSTITUTE OF TECHNOLOGY

UNIVERSITY OF CALIFORNIA

MONTANA STATE UNIVERSITY

UNIVERSITY OF NEVADA, RENO

NEW MEXICO STATE UNIVERSITY

OREGON STATE UNIVERSITY

\author{
UNIVERSITY OF OREGON \\ UNIVERSITY OF SOUTHERN CALIFORNIA \\ STANFORD UNIVERSITY \\ UNIVERSITY OF HAWAII \\ UNIVERSITY OF TOKYO \\ UNIVERSITY OF UTAH \\ WASHINGTON STATE UNIVERSITY \\ UNIVERSITY OF WASHINGTON
}

The Supporting Institutions listed above contribute to the cost of publication of this Journal, but they are not owners or publishers and have no responsibility for its content or policies.

Mathematical papers intended for publication in the Pacific Journal of Mathematics should be in typed form or offset-reproduced, (not dittoed), double spaced with large margins. Please do not use built up fractions in the text of the manuscript. However, you may use them in the displayed equations. Underline Greek letters in red, German in green, and script in blue. The first paragraph or two must be capable of being used separately as a synopsis of the entire paper. Please propose a heading for the odd numbered pages of less than 35 characters. Manuscripts, in triplicate, may be sent to any one of the editors. Please classify according to the scheme of Math. Reviews, Index to Vol. 39. Supply name and address of author to whom proofs should be sent. All other communications should be addressed to the managing editor, or Elaine Barth, University of California, Los Angeles, California, 90024.

50 reprints to each author are provided free for each article, only if page charges have been substantially paid. Additional copies may be obtained at cost in multiples of 50 .

The Pacific Journal of Mathematics is issued monthly as of January 1966. Regular subscription rate: $\$ 102.00$ a year $(6$ Vols., 12 issues). Special rate: $\$ 51.00$ a year to individual members of supporting institutions.

Subscriptions, orders for numbers issued in the last three calendar years, and changes of address shoud be sent to Pacific Journal of Mathematics, P.O. Box 969, Carmel Valley, CA 93924, U.S.A Old back numbers obtainable from Kraus Periodicals Co., Route 100, Millwood, NY 10546.

\section{PUBLISHED BY PACIFIC JOURNAL OF MATHEMATICS, A NON-PROFIT CORPORATION}

Printed at Kokusai Bunken Insatsusha (International Academic Printing Co., Ltd.). 8-8, 3-chome, Takadanobaba, Shinjuku-ku, Tokyo 160, Japan. 


\section{Pacific Journal of Mathematics}

Vol. 93, No. $2 \quad$ April, 1981

Ilya Eugene Blum and Srinivasa Swaminathan, Continuous selections and

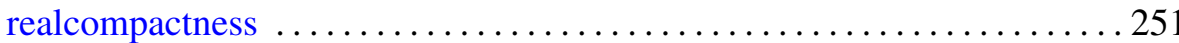

Lawrence James Brenton, Differentiably $k$-normal analytic spaces and extensions of holomorphic differential forms $\ldots \ldots \ldots \ldots \ldots \ldots \ldots 261$

Jo-Ann Deborah Cohen, Topologies on the ring of integers of a global field ................................................... 269

Robert Jay Daverman, Detecting the disjoint disks property $\ldots \ldots \ldots \ldots 277$

Edmund H. Feller, Rings where the annihilators of $\alpha$-critical modules are prime ideals ....................................... 299

Richard Elam Heisey and Henryk Torunczyk, On the topology of direct

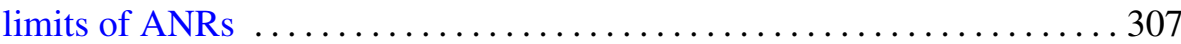

Gerald William Johnson and David Lee Skoug, Notes on the Feynman

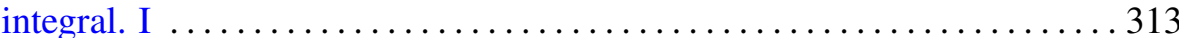

Michael S. Keane and Stuart Jay Sidney, Distinguishing a plane curve

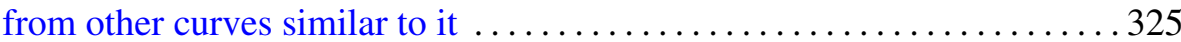

Leonid A. Luxemburg, On compact metric spaces with noncoinciding

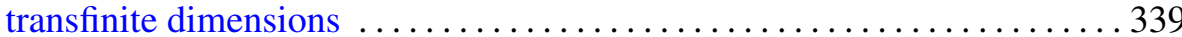

Chun Ming Ma, A uniqueness theorem for Navier-Stokes equations . . . . . . 387

Donald J. Newman and Theodore Joseph Rivlin, A characterization of the weights in a divided difference . . . . . . . . . . . . . . . . . . . 407

Marc Aristide Rieffel, $C^{*}$-algebras associated with irrational rotations $\ldots .415$

Kichi-Suke Saito, Invariant subspaces for finite maximal subdiagonal algebras

Frederic W. Shultz, Dual maps of Jordan homomorphisms and ${ }^{*}$-homomorphisms between $C^{*}$-algebras $\ldots \ldots \ldots \ldots$

Vsevolod Alekseevich Solonnikov, On the solvability of boundary and initial-boundary value problems for the Navier-Stokes system in domains with noncompact boundaries

Tavan Thomas Trent, New conditions for subnormality

L. E. Ward, Extending Whitney maps ..................

Leslie Wilson, Jets with regular zeros

Sergio Eduardo Zarantonello, The sheaf of $H^{p}$-functions in product 